\title{
The aetiology of post-traumatic stress following childbirth: a meta-analysis and theoretical framework
}

\author{
S. Ayers ${ }^{1 *}$, R. Bond ${ }^{2}$, S. Bertullies ${ }^{1}$ and K. Wijma ${ }^{3}$ \\ ${ }^{1}$ Centre for Maternal and Child Health Research, City University London, London, UK \\ ${ }^{2}$ School of Psychology, University of Sussex, Brighton, UK \\ ${ }^{3}$ Unit of Medical Psychology, Department of Clinical and Experimental Medicine, Faculty of Medicine and Health Sciences, Linköping University, \\ Linköping, Sweden
}

\begin{abstract}
There is evidence that $3.17 \%$ of women report post-traumatic stress disorder (PTSD) after childbirth. This meta-analysis synthesizes research on vulnerability and risk factors for birth-related PTSD and refines a diathesis-stress model of its aetiology. Systematic searches were carried out on PsycINFO, PubMed, Scopus and Web of Science using PTSD terms crossed with childbirth terms. Studies were included if they reported primary research that examined factors associated with birth-related PTSD measured at least 1 month after birth. In all, 50 studies $(n=21429)$ from 15 countries fulfilled inclusion criteria. Pre-birth vulnerability factors most strongly associated with PTSD were depression in pregnancy $(r=0.51)$, fear of childbirth $(r=0.41)$, poor health or complications in pregnancy $(r=0.38)$, and a history of PTSD $(r=0.39)$ and counselling for pregnancy or birth $(r=0.32)$. Risk factors in birth most strongly associated with PTSD were negative subjective birth experiences $(r=0.59)$, having an operative birth (assisted vaginal or caesarean, $r=0.48)$, lack of support $(r=-0.38)$ and dissociation $(r=0.32)$. After birth, PTSD was associated with poor coping and stress $(r=0.30)$, and was highly co-morbid with depression $(r=0.60)$. Moderator analyses showed that the effect of poor health or complications in pregnancy was more apparent in high-risk samples. The results of this meta-analysis are used to update a diathesisstress model of the aetiology of postpartum PTSD and can be used to inform screening, prevention and intervention in maternity care.
\end{abstract}

Received 27 September 2015; Revised 1 October 2015; Accepted 11 November 2015; First published online 16 February 2016

Key words: Birth, labour, postpartum depression, post-traumatic stress disorder.

\section{Introduction}

Approximately 136 million women give birth to a live or stillborn baby every year (World Health Organization, 2005) with 4.5 million of these births occurring in North America and 5.4 million in Europe (European Commission, 2011; UNdata, 2011). There is now substantial evidence that women can suffer from a range of psychological problems during this time. Postpartum depression is most widely recognized and affects between 10 and 15\% of women (Gavin et al. 2005). There is also evidence that women are more vulnerable to anxiety and adjustment disorders (Brockington, 2004; Wenzel et al. 2005; Brockington et al. 2006). Maternal mental health problems are usually higher in low- and middle-income countries particularly women in socially and economically disadvantaged circumstances (Fisher et al. 2011).

The causes of maternal mental health problems are multifactorial and include individual vulnerability factors, such as previous psychological problems, and

\footnotetext{
* Address for correspondence: S. Ayers, Centre for Maternal and Child Health Research, City University London, Northampton Square, London EC1V 0HB, UK.

(Email: Susan.Ayers@city.ac.uk)
}

psychosocial circumstances, such as socio-economic deprivation, intimate partner violence or other chronic stressors. In some instances the events of birth may also contribute to postpartum adjustment problems and mental health disorders. There is increasing evidence that some women develop post-traumatic stress disorder (PTSD) in response to events of birth (Ayers \& Pickering, 2001; Alcorn et al. 2010). Reviews of this research suggest it affects $3.17 \%$ of women postpartum (Grekin \& O'Hara, 2014). Unlike other postpartum psychopathology, this is therefore an area where there is clear potential to prevent or minimize postpartum PTSD by changing maternity and early postpartum care to improve women's experiences of birth. However, in order to do this we first need to identify the risk factors for birth-related PTSD.

Conceptual frameworks of the aetiology of postpartum PTSD draw together key vulnerability, risk and maintaining factors that are thought to be important in the development of birth-related PTSD (Ayers, 2004; van Son et al. 2005; Slade, 2006). These usually draw on psychological approaches, such as the diathesis-stress model which explains health outcomes as an interaction between an individual's predispositional vulnerability and stressful experiences. In a previous paper, we used a diathesis-stress approach to propose 
a model of postpartum PTSD that incorporates vulnerability factors in pregnancy, risk factors during birth, and maintaining factors after birth in the onset and maintenance of PTSD (Ayers, 2004). Vulnerability factors in pregnancy were specified as previous psychological problems, a history of trauma or sexual abuse, anxiety and having a first baby (nulliparity). These vulnerability factors are proposed to interact with birth events to determine appraisal of birth as traumatic, and subsequent traumatic stress responses. Birth risk factors were specified as type of birth (as a broad indicator of level of intervention and complications), poor support, high levels of negative emotion, perceived threat, and dissociation. Postpartum factors that might maintain initial PTSD symptoms were specified as additional stress, maladaptive coping and poor support (Ayers, 2004).

Evidence broadly confirms the associations between the factors outlined above and postpartum PTSD (Wijma \& Wijma, 1997; Creedy et al. 2000; Czarnocka \& Slade, 2000; Söderquist et al. 2002, 2009; Cohen et al. 2004; Cigoli et al. 2006; Lev-Wiesel et al. 2009a). Very few studies have looked at the interaction between vulnerability and risk factors. Those studies that have done so are consistent with the idea that trauma history interacts with birth intervention to increase risk of PTSD after birth (Ayers et al. 2009; Ford \& Ayers, 2011). Likewise, support during birth can mediate the relationship between previous trauma and birth-related PTSD; as well as the relationship between birth intervention and postpartum PTSD (Ford \& Ayers, 2011).

Overviews of factors associated with postpartum PTSD have been provided in various narrative reviews (Bailham \& Joseph, 2003; Ayers, 2004; Olde et al. 2006; Andersen et al. 2012) and a meta-analysis (Grekin \& O'Hara, 2014). The meta-analysis looked at risk factors for PTSD in postpartum women who reported PTSD in response to a range of traumatic stressors, including childbirth (Grekin \& O'Hara, 2014). This reviewed 78 studies which reported prevalence and/or risk factors for PTSD and analysed risk factors for PTSD separately in community or high-risk samples. The authors concluded that the main factors associated with PTSD in community samples were birth experiences and postpartum depression. In high-risk samples the main factors were infant complications and postpartum depression. These results of this meta-analysis highlight the co-morbidity between postpartum PTSD and depression, and are broadly consistent with the vulnerability and risk factors outlined in the diathesis-stress model with the exception of parity, which was not found to moderate prevalence rates. However, this meta-analysis did not focus on birthrelated PTSD and therefore understandably did not examine all the factors proposed to be important by models of birth-related PTSD, such as dissociation, postpartum stress and maladaptive coping. The most recent review of evidence focusing on birth-related PTSD was carried out by Andersen et al. (2012) who concluded that subjective distress during labour and obstetric emergencies are the main risk factors for birth-related PTSD. Other risk factors included poor support during birth and complications with the baby. Vulnerability factors were a history of trauma or psychological problems in pregnancy (Andersen et al. 2012). Again, this is broadly consistent with the diathesis-stress model but no meta-analyses were conducted.

These reviews provide useful syntheses of research and promising evidence towards refining the diathesis-stress model of the aetiology of birth-related PTSD. The amount of evidence available means that meta-analyses are now possible and the meta-analysis by Grekin \& O'Hara (2014) provides a valuable overview of postpartum PTSD regardless of the trigger event. What is needed now is a more detailed meta-analysis of all the vulnerability and risk factors for birth-related PTSD proposed by the diathesis-stress model, and examination of a wider range of co-morbid symptoms. Methodological and sampling differences also need to be considered. This review and meta-analysis therefore has three aims. The first is to systematically review and identify the effect sizes for vulnerability and risk factors for birth-related PTSD symptoms and update the diathesis-stress model of birth-related PTSD. The second is to examine the association between birth-related PTSD and co-morbid symptoms. The third is to examine methodological and individual factors that might moderate these relationships. In doing so the review will identify the critical vulnerability and risk factors that put women at risk of developing birth-related PTSD symptoms, and therefore which women may need additional support and care during birth. The results will inform understanding and clinical practice by highlighting vulnerability factors to screen for in pregnancy; those elements of maternity services that can be targeted for most effective prevention; and which vulnerability or risk factors that perinatal psychology services may need to incorporate into assessment and treatment of birth-related PTSD.

\section{Method}

\section{Selection of studies}

A systematic search was conducted to identify studies of PTSD in women following childbirth. Computerized databases PsycINFO, PubMed, Scopus and Web of 
Science were searched up to March 2015 using terms related to PTSD (posttraumatic stress, post-traumatic stress, trauma*, PTSD) crossed with childbirth-related terms (birth, pregnancy, partum, postpartum, prenatal, postnatal, stillbirth, miscarriage, gestation, partus, labor). Additional studies $(n=40)$ were located through inspecting references and citations of key publications. Fig. 1 summarizes results of the search which yielded a preliminary database of 8044 papers. Of these, 6836 were excluded from the title as not relevant to childbirth. These were predominantly animal studies or occupational studies of work labour/labour. This left a database of 1208 papers of which examination of abstracts showed that 785 did not meet inclusion criteria, leaving 423 papers where the full text was examined to determine eligibility.

\section{Inclusion and exclusion criteria}

Inclusion criteria were that papers reported primary research that included a quantitative measure of birthrelated PTSD taken at least 1 month after birth to exclude confounding with acute stress disorder. Research had to be with women 18 years of age or over, and published in English. Papers were excluded if they were qualitative or case studies, reviews or discussion papers, dissertations, conference abstracts, or only measured PTSD in pregnancy. Intervention studies were excluded unless they reported relationships between PTSD and risk factors prior to the intervention $(n=0)$. Control-comparison papers were excluded if the PTSD group was selected on the basis of nonstandard cut-offs for subclinical symptoms. Studies on high-risk samples where all women had experienced pregnancy loss, stillbirth or severe complications with the baby (e.g. all preterm births or very low-birth-weight babies) were excluded to avoid potential confounding with traumatic bereavement or perceived threat to the baby rather than self. It is also possible that different factors are associated with the development of PTSD after loss of a baby (Daugirdaite et al. 2015).

Studies had to report the correlation coefficient $r$ or odds ratio, or sufficient statistical information to compute these statistics. Authors of papers with unclear statistical information $(n=16)$ were contacted to request further information. Half these authors provided the data requested where available $(n=8)^{1}+$. Where data were not available these effects or the study were excluded ( $n=1$; Leeds \& Hargreaves, 2008). Longitudinal studies which measured PTSD at different time points were included and effect sizes taken

+ The notes appear after the main text. from the shortest time between measurement of risk factors and PTSD. Thus concurrent and longitudinal relationships were included in the analyses and time between measures of risk and PTSD was examined as a potential moderator.

\section{Variables coded}

A number of variables were extracted for analysis. Detailed information on coding is given in online Supplementary File S1.

Sample characteristics extracted were: country of origin, clinical status of the sample, age, ethnicity, marital status, education and socio-economic status. Clinical status was classed as low risk, normal risk or high risk.

Methodological variables extracted were: methodological quality, design (cross-sectional or longitudinal), recruitment (antenatal or postnatal), sampling (via the Internet or community), sample size and time-frame of the effect size (i.e. months elapsed between the measure of risk and PTSD).

PTSD measures were coded for quality (0 to 3 ). Questionnaire measures that did not measure all symptoms of PTSD and included items that are not part of diagnostic criteria were scored 0; questionnaire measures of PTSD symptoms but not full diagnostic criteria scored 1; questionnaire measures of all diagnostic criteria scored 2; and clinical interviews scored 3.

Birth variables extracted included: objective birth experience, subjective birth experience, type of birth (operative or normal vaginal), length of labour (hours), pain, complications with the baby, presence of partner, dissociation during birth, and support from staff during birth. Subjective birth experience included: (i) overall ratings of birth experience; (ii) negative emotions and distress; and (iii) control and agency.

Vulnerability factors extracted were in four domains. The first domain was prior history and included history of traumatic events, PTSD, sexual abuse or psychological problems. The second domain was vulnerability due to poor mental health in pregnancy. These variables were depression in pregnancy, anxiety in pregnancy, fear of childbirth and counselling for problems associated with a previous pregnancy/birth. The third domain was pregnancy-related vulnerability which included: being primiparous, whether the pregnancy was planned, poor physical health in pregnancy, and problems in a previous pregnancy/birth. The final domain was psychosocial vulnerability which included coping and stress, and social support.

Co-morbid symptoms included depression, anxiety, general psychological health and physical health.

Potential moderators of clinical status of the sample, quality of PTSD measure, and time between measuring risk factors and PTSD were also extracted. 


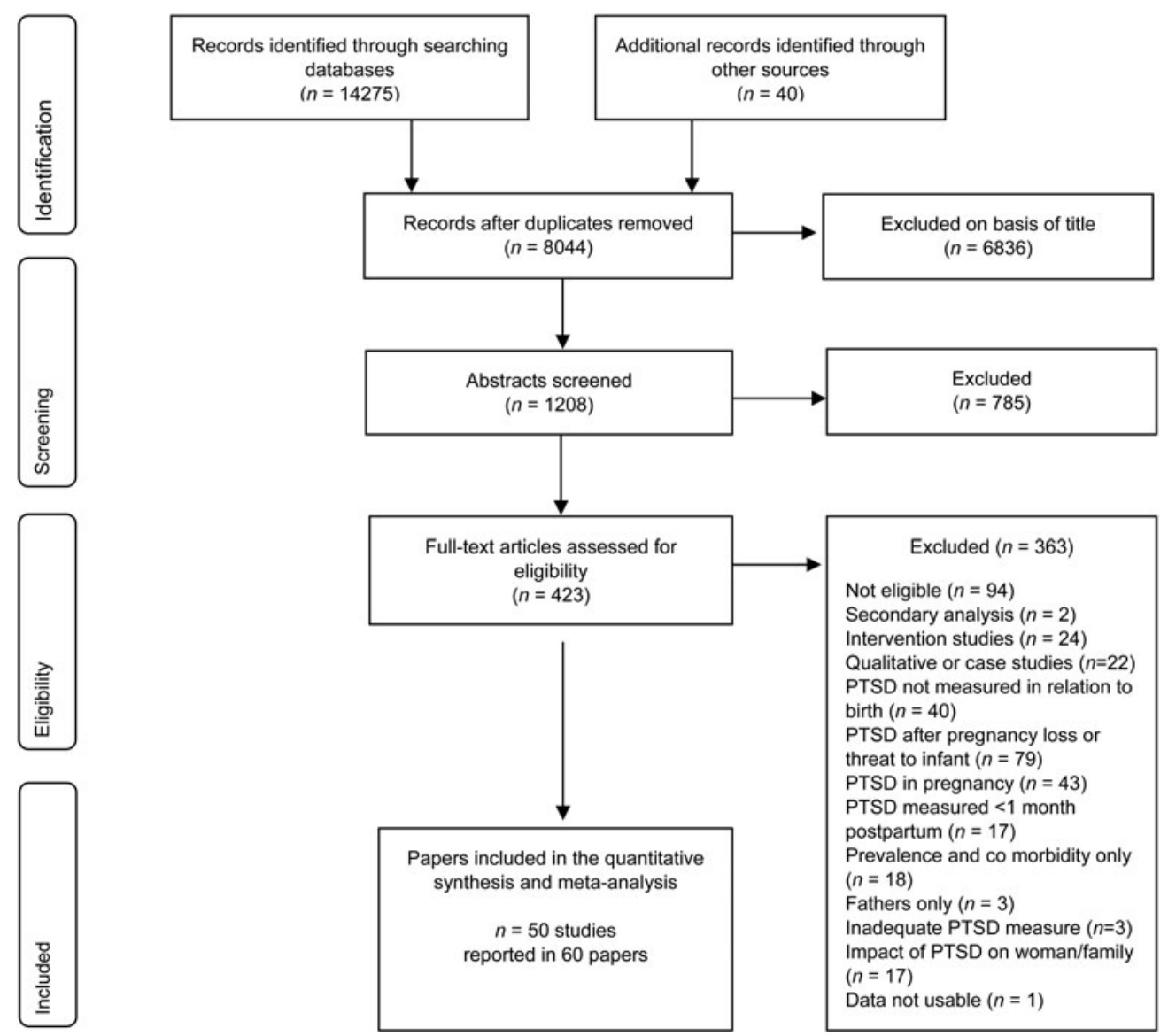

Fig. 1. Flowchart of systematic search. PTSD, Post-traumatic stress disorder.

\section{Methodological quality}

Methodological quality of each study was assessed using a checklist based on Sawyer et al. (2010) and Andersen et al. (2012). Nine criteria were assessed of: clear study aims; clear inclusion/exclusion criteria; method of data collection; measure of PTSD; sample representativeness; response rate; examination of bias in participants who did not take part or dropped out; prospective design; more than one postpartum data collection point (each rated from 0 to 3 ; total score $0-27)$. Most studies were of reasonable or good quality with $70 \%(n=35 / 50)$ scoring over the mid-point of 14 or more (see Table 1).

\section{Computation and analysis of effect sizes}

The majority of effect sizes were reported as Pearson correlation coefficients, although some used odds ratios or rank correlations. Odds ratios were therefore converted to $r$ and rank correlations were treated as equivalent to Pearson correlations ${ }^{2}$. The effect size for all studies was therefore $r$. To ensure this approach did not influence results, we conducted analyses separately for $r$ and odds ratios and they did not differ appreciably. A few studies reported correlation coefficients only for symptom subscales of PTSD. Therefore to guarantee the independence assumption among effect sizes the coefficients were averaged to produce a single effect size associated with overall PTSD.

In meta-analysis, there is a choice between fitting either fixed-effect or random-effect models (Hedges \& Vevea, 1998; Hunter \& Schmidt, 2004; Borenstein et al. 2010). Random-effects models are more usually recommended because it is likely that there is heterogeneity in the population effect sizes as a consequence of differences in, for example, study design and the measures used. However, Hedges \& Vevea (1998) point out that it is not the presence of heterogeneity per se that should influence the choice of a fixed- or a random-effects model. Rather, the issue is which population we wish to make inferences to. In a fixed-effects model, inference is confined to the set of studies included in the analysis whereas in a random-effects model inference can be made to a broader population from which the studies included in the analysis 
Table 1. Characteristics of studies included in the meta-analysis

\begin{tabular}{|c|c|c|c|c|c|c|c|c|}
\hline Study & $n$ & Country & $\begin{array}{l}\text { Mean age, } \\
\text { years (range) }\end{array}$ & $\begin{array}{l}\text { Marital } \\
\text { status, \% } \\
\text { cohabiting }\end{array}$ & $\begin{array}{l}\text { Racial } \\
\text { composition, } \\
\text { \% white }\end{array}$ & $\begin{array}{l}\text { Time } \\
\text { since } \\
\text { birth, } \\
\text { months }^{\text {a }}\end{array}$ & $\begin{array}{l}\text { Measure of } \\
\text { PTSD }\end{array}$ & Quality \\
\hline Adewuya et al. (2006) & 876 & Nigeria & 26.0 (NR) & 85.9 & NR & 1.5 & MINI & 20 \\
\hline $\begin{array}{l}\text { Alcorn et al. (2010); Devilly } \\
\text { et al. (2014); O'Donovan } \\
\text { et al. (2014) }\end{array}$ & 933 & Australia & 28.6 (NR) & 84.0 & 86.0 & $\begin{array}{l}1.3,3.0^{\mathrm{b}} \\
6.0\end{array}$ & PDS & 25 \\
\hline Ayers et al. (2014) & 57 & UK & $33.2(25-46)$ & 100 & 89.6 & 3.0 & PDS & 21 \\
\hline Beck et al. (2011) & 1573 & USA & NR (18-45) & NR & 66.0 & $7.0-18.0^{\mathrm{c}}$ & PSS-SR & 15 \\
\hline Briddon et al. (2011) & 122 & UK & $28.0(18-44)$ & 87.7 & 87.7 & 1.5 & $\begin{array}{l}\text { APTSD-Q, } \\
\text { IES }\end{array}$ & 17 \\
\hline Cigoli et al. (2006) & 160 & Italy & NR (NR) & NR & NR & 4.5 & PTSD-Q & 12 \\
\hline Cohen et al. (2004) & 253 & Canada & NR (NR) & NR & NR & 2.0 & DTS & 19 \\
\hline Creedy et al. (2000) & 592 & Australia & NR (NR) & NR & NR & 1.3 & PSS-I & 14 \\
\hline Czarnocka \& Slade (2000) & 298 & UK & $28.9(18-41)$ & 92.0 & NR & 1.5 & PTSD-Q & 17 \\
\hline Denis et al. (2011) & 239 & France & 30.4 (NR) & 96.0 & NR & $\begin{array}{l}1.0^{\mathrm{b}}, 4.0^{\mathrm{b}} \\
9.0\end{array}$ & IES-R & 14 \\
\hline Edworthy et al. (2008) & 121 & UK & $30.7(16-41)$ & 95.4 & NR & 1.5 & IES-R & 22 \\
\hline Engelhard et al. (2002) & 113 & Netherlands & 31.8 (NR) & 95.8 & NR & 13.7 & PSS-SR & 13 \\
\hline $\begin{array}{l}\text { Fairbrother \& Woody } \\
\text { (2007) }\end{array}$ & 99 & Canada & NR (22-42) & 96 & 86.7 & 1.0 & PSS-SR & 14 \\
\hline $\begin{array}{l}\text { Ford et al. (2010); Ford \& } \\
\text { Ayers (2011) }\end{array}$ & 138 & UK & 32.1 (NR) & 89.1 & 92.6 & 3.0 & PDS & 24 \\
\hline Furuta et al. (2014) & 1824 & UK & 32.3 (NR) & NR & 60.5 & 2.0 & IES & 20 \\
\hline $\begin{array}{l}\text { Garthus-Niegel et al. } \\
\text { (2013); Garthus-Niegel } \\
\text { et al. }(2014 a, b)\end{array}$ & 3751 & Norway & $30.7(17-46)$ & 97.6 & NR & 2.0 & IES & 16 \\
\hline Ghorbani et al. $(2014 a, b)$ & 82 & Iran & 27.9 (NR) & 100 & NR & 2.0 & IES & 12 \\
\hline Goutaudier et al. (2012) & 123 & France & $30.5(19-41)$ & 96 & NR & 1.5 & IES-R & 15 \\
\hline Harris \& Ayers (2012) & 675 & UK & $31.6(19-66)$ & 93.6 & 98.6 & $2.5-566.0^{\mathrm{c}}$ & PDS & 11 \\
\hline Hauer et al. (2009) & 54 & Netherlands & 31.7 (NR) & NR & NR & 1.5 & IES, PSS-SR & 17 \\
\hline Hoedjes et al. (2011) & 128 & Netherlands & 31.0 (NR) & NR & NR & $1.3^{\mathrm{b}}, 3.0$ & SRIP & 17 \\
\hline Iles et al. (2011) & 303 & UK & $31.7(19-44)$ & 100.0 & 97.6 & $1.5^{\mathrm{b}}, 3.0$ & $\begin{array}{l}\text { IES, } \\
\text { PTSD-Q }\end{array}$ & 16 \\
\hline Lemola et al. (2007) & 458 & Switzerland & 32.4 (NR) & 99.5 & NR & 5.0 & IES-R & 14 \\
\hline Leeds \& Hargreaves (2008) & 102 & UK & 30.06 (NR) & 86.3 & NR & $6.0-12.0$ & PPQ, PCL & 12 \\
\hline $\begin{array}{l}\text { Lev-Wiesel et al. }(2009 a, b) \text {; } \\
\text { Lev-Wiesel \& } \\
\text { Daphna-Tekoah }(2010)\end{array}$ & 1586 & Israel & $30.5(18-44)$ & NR & NR & 2.0 & PSS-I & 20 \\
\hline Lyons (1998) & 62 & UK & $29.0(20-39)$ & NR & 100.0 & 1.0 & IES & 17 \\
\hline Maclean et al. (2000) & 40 & UK & 29.2 (NR) & 80.0 & NR & NR & IES & 12 \\
\hline Maggioni et al. (2006) & 93 & Italy & $33.0(20-40)$ & NR & NR & 4.5 & PTSD-Q & 12 \\
\hline Mautner et al. (2013) & 67 & Austria & $32.2(23-43)$ & NR & NR & $1.0-48.0$ & IES & 16 \\
\hline Modarres et al. (2012) & 218 & Iran & 26.9 (NR) & NR & NR & 2.0 & PSS-I & 12 \\
\hline $\begin{array}{l}\text { Noyman-Veksler et al. } \\
\text { (2015) }\end{array}$ & 142 & Israel & 28.7 (NR) & NR & NR & $1.5^{\mathrm{b}}, 3.0$ & PDS & 23 \\
\hline Olde et al. (2005) & 219 & Netherlands & $31.5(22-40)$ & 100 & NR & 3.0 & PSS-SR & 16 \\
\hline Onoye et al. (2009) & 54 & USA & 26.9 (NR) & NR & NR & 1.5 & PCL-C & 14 \\
\hline Polachek et al. (2012) & 102 & Israel & $32.0(20-40)$ & NR & NR & 1.0 & PDS & 13 \\
\hline Ryding et al. (1998) & 354 & Sweden & $29.0(18-46)$ & NR & NR & 1.0 & IES & 17 \\
\hline Sawyer \& Ayers (2009) & 216 & UK & $28.1(18-42)$ & 95.4 & 97.3 & $1.0-36.0^{\mathrm{c}}$ & PDS & 12 \\
\hline Sawyer et al. (2012) & 125 & UK & $31.9(18-42)$ & 88.0 & 88.8 & 2.0 & PSS-SR & 19 \\
\hline $\begin{array}{l}\text { Söderquist et al. (2006); } \\
\text { Söderquist et al. (2009) }\end{array}$ & 1224 & Sweden & 28.6 (NR) & 97 & NR & $\begin{array}{r}1.0^{\mathrm{b}}, 4.0 \\
7.0,11.0\end{array}$ & TES & 22 \\
\hline
\end{tabular}


Table 1 (cont.)

\begin{tabular}{|c|c|c|c|c|c|c|c|c|}
\hline Study & $n$ & Country & $\begin{array}{l}\text { Mean age, } \\
\text { years (range) }\end{array}$ & $\begin{array}{l}\text { Marital } \\
\text { status, \% } \\
\text { cohabiting }\end{array}$ & $\begin{array}{l}\text { Racial } \\
\text { composition, } \\
\text { \% white }\end{array}$ & $\begin{array}{l}\text { Time } \\
\text { since } \\
\text { birth, } \\
\text { months }^{\text {a }}\end{array}$ & $\begin{array}{l}\text { Measure of } \\
\text { PTSD }\end{array}$ & Quality \\
\hline $\begin{array}{l}\text { Sorenson \& Tschetter } \\
\text { (2010) }\end{array}$ & 71 & USA & $30.0(22-42)$ & NR & NR & 6.5 & PTCS & 10 \\
\hline $\begin{array}{l}\text { Stramrood et al. (2011); } \\
\text { Warmelink et al. (2012) }\end{array}$ & 428 & Netherlands & $32.0(17-45)$ & 96.5 & NR & $2.0-6.0^{c}$ & TES & 14 \\
\hline Stramrood et al. (2011) & 193 & Netherlands & 30.7 (NR) & 95.9 & NR & $1.5^{\mathrm{b}}, 15.0$ & PSS-SR & 20 \\
\hline Sumner et al. (2012) & 210 & USA & 27.7 (NR) & NR & 0 & $7.0^{\mathrm{b}}, 13.0$ & PCL-C & 15 \\
\hline Suttora et al. (2014) & 243 & Italy & 34.3 (NR) & 99.2 & NR & $1.0-36.0^{\mathrm{b}}$ & PPQ & 11 \\
\hline Tham et al. (2007) & 129 & Sweden & $32.7(21-45)$ & 95 & NR & 3.0 & IES & 18 \\
\hline van Son et al. (2005) & 248 & Netherlands & $31.0(19-43)$ & NR & NR & $\begin{array}{l}3.0^{\mathrm{b}}, 6.0 \\
12.0\end{array}$ & IES & 18 \\
\hline Verreault et al. (2012) & 367 & Canada & $32.2(19-44)$ & 97.1 & 77.7 & $\begin{array}{l}1.3^{\mathrm{b}}, 3.0 \\
6.0\end{array}$ & PSS-SR & 20 \\
\hline $\begin{array}{l}\text { Vossbeck-Elsebusch et al. } \\
\text { (2014) }\end{array}$ & 224 & Germany & 30.54 (NR) & 72.3 & NR & $1.0-6.0^{\mathrm{b}}$ & PDS & 13 \\
\hline $\begin{array}{l}\text { Wijma et al. (1997); } \\
\text { Söderquist et al. (2002) }\end{array}$ & 1640 & Sweden & $28.7(17-45)$ & 96.0 & NR & $1.0-15.0^{\mathrm{C}}$ & TES & 18 \\
\hline Wijma et al. (2002) & 40 & Sweden & $30.0(19-43)$ & 93.0 & NR & 1.0 & IES & 19 \\
\hline Zaers et al. (2008) & 60 & Switzerland & $30.6(19-42)$ & 94.0 & NR & $1.5^{\mathrm{b}}, 6.0$ & PDS & 13 \\
\hline
\end{tabular}

PTSD, Post-traumatic stress disorder; Quality, Methodological Quality Score, possible scores: 0-27; NR, not reported in the study; MINI, MINI International Neuropsychiatric Interview; PDS, Posttraumatic Diagnostic Scale; PSS-SR, Post-Traumatic Stress Disorder Symptom Scale-Self Report; APTSD-Q, Adjusted Post-Traumatic Stress Disorder Questionnaire; IES, Impact of Event Scale (original version); PTSD-Q, Post-Traumatic Stress Disorder Questionnaire; DTS, Davidson Trauma Scale; IES-R, Impact of Event Scale (revised version); SRIP, Self-Rating Inventory for Posttraumatic Stress Disorder; PPQ, Perinatal PTSD Questionnaire; PCL, Posttraumatic Stress Disorder Checklist; PSS-I, Posttraumatic Stress Scale Interview; PCL-C, Posttraumatic Stress Disorder Checklist-Civilian Version; TES, Traumatic Event Scale; PTCS, Posttraumatic Childbirth Stress Inventory.

a Timing of PTSD measure.

${ }^{\mathrm{b}}$ For longitudinal studies, time point(s) used for analysis.

${ }^{\mathrm{c}}$ Time point not coded for analysis if range greater than 3 months.

may be considered a random sample. However, a random-effects model can be problematic when the number of studies is small because, in comparison with a fixed-effects model, the variability between population effect sizes is also estimated and, with limited numbers of studies, this estimate will be imprecise and can provide misleading results (Borenstein et al. 2009). We therefore decided to use a fixed-effects model and confine inference to the set of study characteristics present in our sample ${ }^{3}$. In analysing correlations, we use the Fisher $z$ transformation for the analysis (Lipsey \& Wilson, 2001) and an integral $z$-to- $r$ transformation for converting our results back to the $r$ metric (Hafdahl, 2009). Moderator analyses were also conducted using a fixed-effects general linear model on the $z$-transformed effect size. Analyses were carried out with the Metafor package in $\mathrm{R}$ (Viechtbauer, 2010).

\section{Results}

\section{Study characteristics}

In all, 50 studies, reported in 60 papers, met inclusion criteria with a total of 21429 participants. Studies included in the meta-analysis are listed in Table 1. Sample sizes of studies ranged from 40 to 3751 and studies were carried out in the UK $(n=12)$, the Netherlands $(n=7)$, Sweden $(n=6)$, USA $(n=4)$, Canada $(n=3)$, Israel $(n=3)$, Italy $(n=3)$, Australia $(n=2)$, France $(n=2)$, Iran $(n=2)$, Switzerland $(n=2)$, Austria $(n=1)$, Germany $(n=1)$, Norway $(n=1)$ and Nigeria $(n=1)$. Most studies were longitudinal $(n=36$, $72 \%)$. Samples predominantly included white women (range 0 to $100 \%$; mean $80.65 \%$ white) with a mean age of 30.41 (S.D. $=1.82$ ) years. Women were mostly cohabiting or married (range 80 to $100 \%$, mean $93.36 \%)$. On average, $32.76 \%$ of samples had 
university-level qualifications (range 7.6 to $68.5 \%$ ). Most studies were on normal populations, with 10 $(20 \%)$ on high-risk groups and three $(6 \%)$ on low-risk groups. Samples were mixed in terms of parity (range 21 to $100 \%$ primiparous, mean $58.47 \%$ ).

\section{Vulnerability and risk factors for postpartum PTSD}

The results of the meta-analyses are shown in Table 2 which gives the number of effects included $(k)$, the effect size $(r)$, and lower and upper confidence limits of the effect size. In this analysis, $k$ is equivalent to the number of studies because only one effect was entered per study. $Q_{\mathrm{e}}$ gives the residual heterogeneity so if it is significant it suggests the heterogeneity in effect sizes is greater than expected from sampling variation and there are likely to be moderators of the effect.

Vulnerability factors during pregnancy that were most strongly associated with birth-related PTSD were depression in pregnancy (0.51), fear of childbirth (0.41), poor health or complications in pregnancy (0.38), a history of PTSD (0.39) or previous counselling for pregnancy or birth-related factors (0.32). Risk factors during birth most strongly associated with PTSD were subjective birth experience (0.59), operative birth (0.48), lack of support from staff during birth $(-0.38)$ and dissociation (0.32). The effect of subjective birth experience was mostly due to negative emotions during birth (0.34) but lack of control or agency was also important $(-0.23)$. After birth, PTSD symptoms were associated with depression (0.60) and poor coping and stress (0.30). PTSD was not associated with time since birth, although this is only based on two studies so should be interpreted with caution. Vulnerability and risk factors with the strongest effect sizes are summarized in Fig. 2.

One study in the meta-analysis was carried out in Nigeria (Adewuya et al. 2006) which has a different social demographic and increased risk of maternal and infant morbidity compared with other studies. To check that this Nigerian study was not unduly influencing results it was removed and analyses repeated. When this study was removed effect sizes became smaller for poor health/complications in pregnancy $[k=$ $8, r=0.23,95 \%$ confidence interval (CI) $0.20-0.26$ ] but larger for control or agency in birth $(k=4, r=-0.35,95 \%$ CI -0.42 to -0.28$)$ and education level $(k=5, r=-0.25$, $95 \%$ CI -0.29 to -0.22$)$.

\section{Moderator analyses}

Moderator analyses examined whether methodological variables had an impact on the relationships between risk factors and PTSD. Moderators examined were clinical status of the sample, quality of PTSD measure, and time between measuring risk factors and PTSD. Results showed that the amount of time between measuring risk factors and postpartum PTSD significantly moderated many effects (see online Supplementary File S2). This means that the strength of the relationship between PTSD and some risk factors changed significantly over time, irrespective of whether this relationship was originally significant. Medium or large moderation effects of time since birth (i.e. greater than 0.3 ) showed that more time since birth reduced the effects of subjective birth experience $(-0.37)$; but increased the effect of a history of sexual trauma (0.30). Clinical status of the sample moderated a few effects. Studies with high-risk samples, such as women who had pre-eclampsia or emergency caesarean sections, were more likely to find associations between PTSD and marital status (0.43), poor health/complications in pregnancy (0.55) and negative emotions in birth (0.32). These latter two are perhaps unsurprising as these factors are likely to be more prevalent in high-risk samples.

Measures of PTSD that used full diagnostic criteria were more likely to find effects between postpartum PTSD and poor health or complications in pregnancy. Conversely, measures that only looked at PTSD symptoms were more likely to find effects between PTSD and marital status $(-0.43)$, previous counselling for pregnancy or birth-related factors $(-0.59)$, stress and coping $(-0.38)$, postpartum emotional health $(-0.48)$ and marital status $(-0.43)$.

\section{Publication bias}

Meta-analysis relies on the published literature so any biases in the selection of studies for publication will be reflected in the studies included in the meta-analysis. Tests of publication bias (see online Supplementary File S3) suggested that some effect sizes might be affected by publication bias, such as those for educational level, ethnicity, history of sexual trauma, type of birth, infant-related complications and depression after childbirth. However, trim-and-fill methods did not result in substantial changes to most effect sizes with only a few analyses where there was funnel plot asymmetry and where trim and fill was indicated. This suggests that the majority of findings are quite robust. The result of analyses where trim and fill was indicated was that the small effects between PTSD and age and planned pregnancy became nonsignificant; and the association between PTSD and socio-economic status, length of labour, and poor postpartum emotional health became significant.

\section{Discussion}

This meta-analysis aimed to quantify the key vulnerability and risk factors for postpartum PTSD, comorbidity and potential moderators of these 
Table 2. Meta-analysis of factors associated with postpartum PTSD (fixed-effects model)

\begin{tabular}{|c|c|c|c|c|c|c|}
\hline & \multirow[b]{2}{*}{$k$} & \multirow[b]{2}{*}{$n$} & \multirow[b]{2}{*}{ Mean effect size: $r$} & \multicolumn{2}{|l|}{$95 \% \mathrm{CI}$} & \multirow[b]{2}{*}{$Q_{\mathrm{e}} \mathrm{df}=(k-1)$} \\
\hline & & & & LL & $\mathrm{UL}$ & \\
\hline \multicolumn{7}{|l|}{ Vulnerability factors } \\
\hline Age & 12 & 6196 & $-0.03^{*}$ & -0.06 & -0.01 & $39.36^{*}$ \\
\hline Educational level $^{\mathrm{a}}$ & 6 & 3713 & $-0.19^{*}$ & -0.22 & -0.16 & $133.22^{*}$ \\
\hline Ethnicity & 7 & 4348 & $0.16^{*}$ & 0.14 & 0.19 & $94.55^{*}$ \\
\hline Marital status & 2 & 1762 & 0.04 & -0.01 & 0.08 & $20.22^{*}$ \\
\hline Socio-economic status & 6 & 2737 & -0.01 & -0.05 & 0.03 & $120.01^{*}$ \\
\hline Previous PTSD & 8 & 5807 & $0.39^{* b}$ & 0.37 & 0.41 & $655.85^{*}$ \\
\hline History of trauma (general) & 14 & 4852 & $0.16^{*}$ & 0.14 & 0.19 & $58.85^{*}$ \\
\hline History of sexual trauma & 8 & 6531 & $0.17^{*}$ & 0.15 & 0.20 & $26.46^{*}$ \\
\hline Previous counselling for pregnancy or birth & 4 & 2917 & $0.32^{* \mathrm{~b}}$ & 0.29 & 0.35 & $270.29^{*}$ \\
\hline Previous psychological problems & 6 & 4458 & $0.25^{*}$ & 0.23 & 0.28 & $92.70^{*}$ \\
\hline Social support (general) & 16 & 6125 & $-0.19^{*}$ & -0.21 & -0.16 & $124.60^{*}$ \\
\hline \multicolumn{7}{|l|}{ Pregnancy-related vulnerability factors } \\
\hline Parity & 12 & 7654 & $0.08^{*}$ & 0.06 & 0.10 & $168.12^{*}$ \\
\hline Pregnancy planned? & 5 & 2107 & $0.07^{*}$ & 0.02 & 0.11 & $95.85^{*}$ \\
\hline Poor health or complications in pregnancy ${ }^{\mathrm{a}}$ & 9 & 4152 & $0.38^{* \mathrm{~b}}$ & 0.35 & 0.40 & $439.91^{*}$ \\
\hline Fear of childbirth & 6 & 5669 & $0.41^{* \mathrm{~b}}$ & 0.39 & 0.43 & $155.09^{*}$ \\
\hline Depression in pregnancy & 12 & 8093 & $0.51^{* b}$ & 0.50 & 0.53 & $591.67^{*}$ \\
\hline \multicolumn{7}{|l|}{ Risk factors during birth } \\
\hline Operative birth & 13 & 4904 & $0.48^{* \mathrm{~b}}$ & 0.46 & 0.50 & $337.29^{*}$ \\
\hline Pain & 16 & 8491 & $0.16^{*}$ & 0.13 & 0.18 & $58.98^{*}$ \\
\hline Length of labour & 6 & 3189 & $-0.05^{*}$ & -0.09 & -0.02 & $95.67^{*}$ \\
\hline Place of birth & 3 & 774 & $0.10^{*}$ & 0.02 & 0.19 & 0.56 \\
\hline Infant-related complications & 17 & 3354 & $0.23^{*}$ & 0.20 & 0.26 & $172.56^{*}$ \\
\hline Subjective birth experience (overall) & 6 & 4622 & $0.59^{* b}$ & 0.58 & 0.61 & $183.61^{*}$ \\
\hline Negative emotions & 7 & 3691 & $0.34^{* \mathrm{~b}}$ & 0.31 & 0.36 & $124.32^{*}$ \\
\hline Control or agency ${ }^{\mathrm{a}}$ & 5 & 1502 & $-0.23^{*}$ & -0.28 & -0.18 & $33.48^{*}$ \\
\hline Objective birth experience & 14 & 8171 & $0.25^{*}$ & 0.23 & 0.27 & $178.65^{*}$ \\
\hline Dissociation & 7 & 2964 & $0.32^{* \mathrm{~b}}$ & 0.29 & 0.35 & $118.25^{*}$ \\
\hline Presence of partner/companion at birth & 2 & 1903 & 0.04 & -0.01 & 0.08 & $5.44^{*}$ \\
\hline Support from staff during birth & 8 & 1868 & $-0.38^{* \mathrm{~b}}$ & -0.41 & -0.34 & $61.15^{*}$ \\
\hline \multicolumn{7}{|l|}{ Postpartum factors and co-morbidity } \\
\hline Depression after childbirth & 11 & 3162 & $0.60^{* \mathrm{~b}}$ & 0.57 & 0.62 & $99.37^{*}$ \\
\hline Anxiety & 10 & 6765 & $0.18^{*}$ & 0.15 & 0.20 & $673.23^{*}$ \\
\hline Postpartum physical complications & 5 & 3794 & $0.06^{*}$ & 0.03 & 0.09 & $18.22^{*}$ \\
\hline Postpartum mental health & 7 & 2017 & $0.27^{*}$ & 0.23 & 0.31 & $31.59^{*}$ \\
\hline Poor coping and stress ${ }^{c}$ & 10 & 2688 & $0.30^{* \mathrm{~b}}$ & 0.27 & 0.33 & $316.42^{*}$ \\
\hline Emotional health & 4 & 434 & 0.05 & -0.04 & 0.15 & $33.50^{*}$ \\
\hline Time since birth & 2 & 885 & 0.00 & -0.06 & 0.07 & 0.86 \\
\hline
\end{tabular}

PTSD, Post-traumatic stress disorder; $k$, number of effect sizes; CI, confidence interval; LL, lower confidence limit of the effect size; UL, upper confidence limit of the effect size; $Q$, heterogeneity statistic; df, degrees of freedom.

${ }^{a}$ When the study from Nigeria (Adewuya et al. 2006) was removed effect sizes differed slightly for poor health/complications in pregnancy $(k=8, r=0.23,95 \%$ CI $0.20-0.26)$, control or agency in birth $(k=4, r=-0.35, \mathrm{CI}-0.42$ to -0.28$)$ and education level $(k=5, r=-0.25,95 \% \mathrm{CI}-0.29$ to -0.22$)$.

${ }^{\mathrm{b}}$ Medium effect sizes of $\geqslant 0.3$.

${ }^{c}$ Poor coping and stress were measured in pregnancy and after birth in different studies.

$* p \leqslant 0.05$.

relationships. Results confirm that pre-birth and birth factors are important, and that PTSD is associated with poor coping and stress after birth and is highly co-morbid with depression in pregnancy and after birth. These results extend our understanding of postpartum PTSD in a number of ways. First, many of the risk factors identified are consistent with the diathesisstress model (Ayers, 2004) and have been used to 


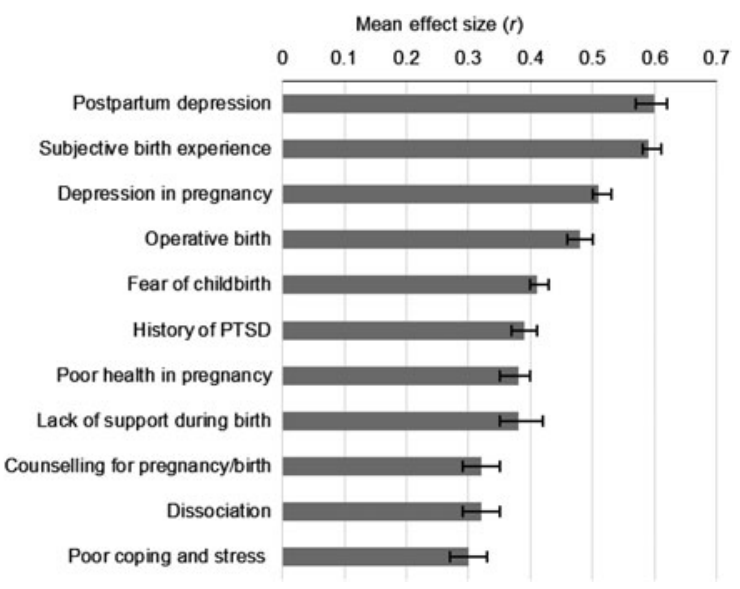

Fig. 2. Effect size $(r)$ for factors with largest associations with postpartum post-traumatic stress disorder (PTSD).

update this model as shown in Fig. 3. The revised model now includes factors identified as having the strongest associations with postpartum PTSD, as well as incorporating a pathway to indicate that vulnerability factors may make an impact on whether women with initial PTSD symptoms resolve their symptoms or develop chronic PTSD. The finding that previous counselling for pregnancy or birth-related factors is a risk factor is probably because this identifies women with previous traumatic birth and/or severe fear of childbirth. This has therefore been subsumed in the model as part of the broader category of fear of childbirth. The results of the meta-analysis therefore help refine our understanding of the aetiology of postpartum PTSD.

Second, this meta-analysis identifies factors that could be used for screening, prevention and treatment of birth-related PTSD. Women can be assessed during and after pregnancy for their level of risk. During pregnancy, women could be assessed for depression, fear of childbirth, poor health or complications, and a history of PTSD. If women score high on these factors steps could be taken to reduce the likelihood of them developing PTSD following childbirth. During birth, women who have operative births or show signs of dissociation could be flagged for postpartum follow-up to assess for PTSD. After birth, women could be asked about their subjective birth experiences. The exact nature that these assessments take and which steps are most effective in preventing or minimizing PTSD symptoms require further research. However, the results of this meta-analysis provide a preliminary basis on which to base screening, prevention or treatment.

The role of support during birth is important as a potential protective factor because it can be relatively easily addressed in maternity care. Perceived support during birth was associated with reduced PTSD and previous research suggests that perceived support is even more important for women with a history of trauma or those who have more intervention during birth (Ford \& Ayers, 2011). General perceived support during and after pregnancy was also associated with reduced PTSD. However, it is not clear from this meta-analysis whether this association reflects a protective function of support or negative impact of poor support contributing to PTSD. There is evidence to substantiate both views. For example, a study of women's worst hotspots during birth (defined as peak emotional distress) found that over a third of hotspots were due to interpersonal factors such as feeling abandoned, being ignored and lacking support (Harris \& Ayers, 2012). Similarly, in the PTSD literature there is evidence that interpersonal traumas where a person is perceived as the perpetrator are more likely to result in PTSD (Charuvastra \& Cloitre, 2008). Conversely, there is evidence from experimental studies using birth stories that positive support may be critical in improving women's perceived control and reducing perceived trauma (Ford \& Ayers, 2009). It is therefore important to look at ways that we can increase support for women during birth - particularly for vulnerable women - whilst at the same time reducing the incidence of poor support.

The results of this review therefore extend our knowledge of birth-related PTSD. However, a number of conceptual and methodological issues need to be considered before drawing conclusions. Conceptually childbirth differs from other traumatic events in that it is experienced as positive by many women and viewed positively by society. Childbirth also involves huge physiological changes that may affect women's responses. Normal postpartum symptoms such as sleep deprivation or increased vigilance may confound measurement of PTSD (Ayers et al. 2015). The baby might also act as a reminder of the birth - therein affecting symptoms of avoidance. Results from this meta-analysis may therefore not be generalizable to PTSD following other events. Despite this, many of the risk factors identified are similar to those found in meta-analyses of postpartum PTSD with a range of traumatic stressors (Grekin \& O'Hara, 2014) and PTSD in non-obstetric samples (Brewin et al. 2000; Ozer et al. 2003). Childbirth also offers an accessible way to prospectively study responses to stressful and potentially traumatic events, as evidenced by the predominance of longitudinal studies in this review.

Moderator analyses (shown in online Supplementary File S2) suggest that some associations are influenced by type of sample, measurement and time since birth. High-risk samples and those using diagnostic interviews were more likely to find an association between poor health or complications in pregnancy and PTSD. This is probably because a few studies, such as the 


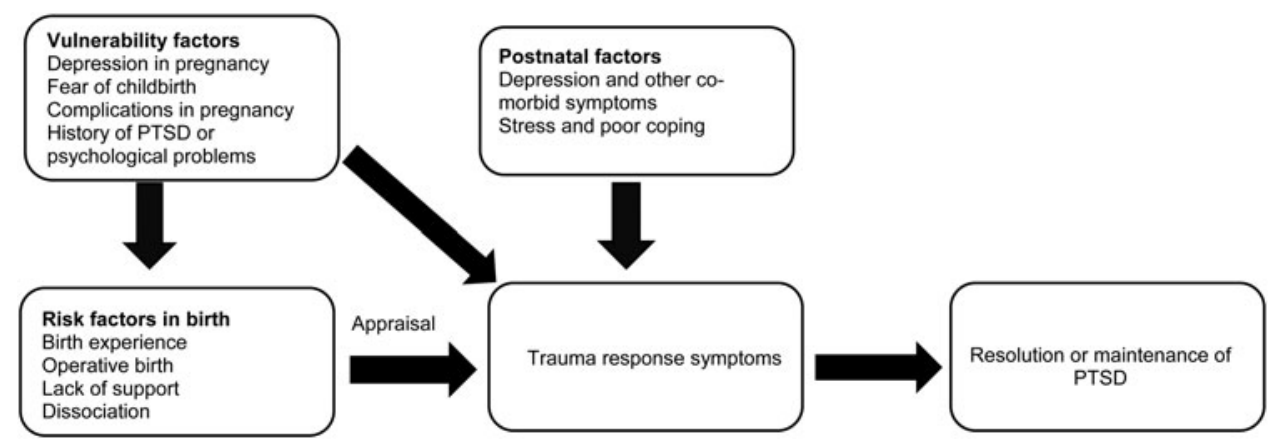

Fig. 3. Revised diathesis-stress model of the aetiology of birth-related post-traumatic stress disorder (PTSD).

Nigerian study by Adewuya et al. (2006), were on highrisk samples (that are more likely to experience complications in pregnancy) and used diagnostic interviews to measure PTSD. Indeed, removing the Nigerian study from the bivariate analyses showed that the effect of complications in pregnancy reduced and the effects of control in birth increased. This suggests that there may be differences in some risk factors between lowand middle-income countries and high-income countries. This is plausible given different rates of maternal morbidity and mortality in these countries.

Moderator analyses of time since birth suggest that the association between birth factors and PTSD reduces over time, whereas the associations with prebirth vulnerability, such as sexual trauma, and postpartum factors may increase over time. This is consistent with theories of PTSD which distinguish between factors associated with the onset and maintenance of PTSD (Ehlers \& Clark, 2000). However, these theories typically emphasize cognitive and coping factors that maintain PTSD, and there is evidence to support that these are important in postpartum PTSD (Ford et al. 2010; Vossbeck-Elsebusch et al. 2014). However, these moderator analyses suggest that preexisting vulnerability and other postpartum factors may also be important in the resolution of postpartum PTSD.

Methodological issues with this review include that some analyses were based on small numbers of studies so results should be interpreted with caution. This is particularly the case for time since birth and sociodemographic variables so further research is needed examining these. Similarly, studies included in the meta-analysis used diverse measures of similar constructs which were difficult to combine. Therefore some agreement over which measures are most appropriate and valid to use in this population would be useful. Finally, we can only analyse and comment on the variables included in research. It is likely that there are variables that warrant further exploration which are not analysed here because of insufficient evidence. For example, cognitive appraisals after birth
(Ford et al. 2010; Vossbeck-Elsebusch et al. 2014), anxiety sensitivity (Keogh et al. 2002; Verreault et al. 2012) and insomnia (Garthus-Niegel et al. 2013) all appear promising but there was not enough evidence to include them in the meta-analysis. Future research should therefore consider other variables, such as these, which are not included in this review. Finally, little research is available from low- and middle-income countries so these findings may only be generalizable to American, European and Australasian populations.

Despite these caveats, it can be seen that this meta-analysis has a number of implications for clinical practice and research. This review identifies a number of vulnerability and risk factors for postpartum PTSD that can be used to inform our understanding of the aetiology of birth-related PTSD, as well as assessment, prevention and intervention. Although PTSD following birth is unique in some ways, results are broadly comparable with meta-analyses of risk factors for PTSD following other events, which suggests that results might be generalizable. Postpartum PTSD offers a useful paradigm to study responses to stressful and potentially traumatic events prospectively. Support during birth may be a particularly promising area for preventing PTSD and the same might be the case for postpartum support and care but more research is needed.

\section{Supplementary material}

For supplementary material accompanying this paper visit http://dx.doi.org/10.1017/S0033291715002706

\section{Acknowledgements}

We are very grateful to Caroline Childerley, Celine Chhoa, Michelle McKenner, Alexandra Thornton and Sarah Woodhouse for their help in carrying out this review.

\section{Declaration of Interest}

None. 


\section{Notes}

${ }^{1}$ We are very grateful to the following authors who were generous enough to provide additional information: Cheryl Beck, Rachel Lev-Weisel and Shir Dafna-Tekoha, Debra Creedy, Anne Denis, Nichole Fairbrother, Claire Stramrood, Pauline Slade, Natalene Sejourne, Stefanie Zaers and Inbal Shlomi.

2 The formula used was $r=\cos (180 /(1+\operatorname{sqrt}(a d / b c))$, where $a d / b c$ is the odds ratio.

${ }^{3}$ We ran all analyses using both a fixed-effects and randomeffects model [using a restricted maximum likelihood (REML) estimator of population heterogeneity]. On the whole, the choice of model made little difference to our conclusions.

\section{References}

Adewuya AO, Ologun YA, Ibigbami OS (2006).

Post-traumatic stress disorder after childbirth in Nigerian women: prevalence and risk factors. BJOG: An International Journal of Obstetrics and Gynaecology 113, 284-288.

Alcorn KL, O'Donovan A, Patrick JC, Creedy D, Devilly GJ (2010). A prospective longitudinal study of the prevalence of post-traumatic stress disorder resulting from childbirth events. Psychological Medicine 40, 1849-1859.

Andersen LB, Melvaer LB, Videbech P, Lamont RF, Joergensen JF (2012). Risk factors for developing post-traumatic stress disorder following childbirth: a systematic review. Acta Obstetricia et Gynecologica Scandinavica 91, 1261-1272.

Ayers S (2004). Delivery as a traumatic event: prevalence, risk factors, and treatment for postnatal posttraumatic stress disorder. Clinical Obstetrics and Gynecology 47, 552-567.

Ayers S, Harris R, Sawyer A, Parfitt Y, Ford E (2009). Posttraumatic stress disorder after childbirth: analysis of symptom presentation and sampling. Journal of Affective Disorders 119, 200-204.

Ayers S, Jessop D, Pike A, Parfitt Y, Ford E (2014). The role of adult attachment style, birth intervention and support in posttraumatic stress after childbirth: a prospective study. Journal of Affective Disorders 155, 295-298.

Ayers S, Pickering AD (2001). Do women get posttraumatic stress disorder as a result of childbirth? A prospective study of incidence. Birth 28, 111-118.

Ayers S, Wright DB, Ford E (2015). Traumatic birth and hyperarousal symptoms: are they normal or pathological? Journal of Reproductive and Infant Psychology, Special Issue 33, 282-293.

Bailham D, Joseph S (2003). Post-traumatic stress following childbirth: a review of the emerging literature and directions for research and practice. Psychology, Health and Medicine 8, 159-168.

Beck CT, Gable RK, Sakala C, Declercq ER (2011). Posttraumatic stress disorder in new mothers: results from a two-stage U.S. national survey. Birth: Issues in Perinatal Care 38, 216-227.
Borenstein M, Hedges LV, Higgins JPT, Rothstein HR (2009). Introduction to Meta-Analysis. Wiley: Chichester, UK.

Borenstein M, Hedges LV, Higgins JPT, Rothstein HR (2010). A basic introduction to fixed-effect and random-effects models for meta-analysis. Research Synthesis Methods 1, 97-111.

Brewin CR, Andrews B, Valentine JD (2000). Meta-analysis of risk factors for posttraumatic stress disorder in trauma-exposed adults. Journal of Consulting and Clinical Psychology 68, 748-766.

Briddon E, Slade P, Isaac C, Wrench I (2011). How do memory processes relate to the development of posttraumatic stress symptoms following childbirth? Journal of Anxiety Disorders 25, 1001-1007.

Brockington I (2004). Postpartum psychiatric disorders. Lancet 363, 303-310.

Brockington IF, Macdonald E, Wainscott G (2006). Anxiety, obsessions and morbid preoccupations in pregnancy and the puerperium. Archives of Women's Mental Health 9, 253-263.

Charuvastra A, Cloitre M (2008). Social bonds and posttraumatic stress disorder. Annual Review of Psychology 59, 301-328.

Cigoli V, Gilli G, Saita E (2006). Relational factors in psychopathological responses to childbirth. Journal of Psychosomatic Obstetrics and Gynaecology 27, 91-97.

Cohen MM, Ansara D, Schei B, Stuckless N, Stewart DE (2004). Posttraumatic stress disorder after pregnancy labor, and delivery. Journal of Women's Health 13, 315-324.

Creedy DK, Shochet IM, Horsfall J (2000). Childbirth and the development of acute trauma symptoms: incidence and contributing factors. Birth: Issues in Perinatal Care 27, 104-111.

Czarnocka J, Slade P (2000). Prevalence and predictors of posttraumatic stress symptoms following childbirth. British Journal of Clinical Psychology 39, 35-51.

Daugirdaite V, van den Akker O, Purewal S (2015). Posttraumatic stress and posttraumatic stress disorder after termination of pregnancy and reproductive loss: a systematic review. Journal of Pregnancy 2015, article ID 646345.

Denis A, Parant O, Callahan S (2011). Post-traumatic stress disorder related to birth: a prospective longitudinal study in a French population. Journal of Reproductive and Infant Psychology 29, 125-135.

Devilly GJ, Gullo MJ, Alcorn KL, O'Donovan A (2014). Subjective appraisal of threat (criterion A2) as a predictor of distress in childbearing women. Journal of Nervous and Mental Disease 202, 877-882.

Edworthy Z, Chase R, Williams H (2008). The role of schema and appraisals in the development of post-traumatic stress symptoms following birth. Journal of Reproductive and Infant Psychology 26, 123-138.

Ehlers A, Clark DM (2000). A cognitive model of posttraumatic stress disorder. Behaviour Research and Therapy 38, 319-345.

Engelhard IM, Van Rij M, Boullart I, Ekhart THA, Spaanderman MEA, Van den Hout MA, Peeters LLH (2002). Posttraumatic stress disorder after pre-eclampsia: an exploratory study. General Hospital Psychiatry 24, 260-264. 
European Commission (2011). Demography Report 2010 Older, More Numerous and Diverse Europeans. Publications Office of the European Union: Luxembourg.

Fairbrother N, Woody SR (2007). Fear of childbirth and obstetrical events as predictors of postnatal symptoms of depression and post-traumatic stress disorder.

Journal of Psychosomatic Obstetrics and Gynaecology 28, 239-242.

Fisher J, Cabral de Mello M, Patel V, Rahman A, Tran T, Holton S, Holmes W (2011). Prevalence and determinants of common perinatal mental disorders in women in low- and lower-middle-income countries: a systematic review. Bulletin of the World Health Organization 90, 139G-149G.

Ford E, Ayers S (2009). Stressful events and support during birth: the effect on anxiety, mood, and perceived control. Journal of Anxiety Disorders 23, 260-268.

Ford E, Ayers S (2011). Support during birth interacts with prior trauma and birth intervention to predict postnatal post-traumatic stress symptoms. Psychology and Health 26, 1553-1570.

Ford E, Ayers S, Bradley R (2010). Exploration of a cognitive model to predict post-traumatic stress symptoms following childbirth. Journal of Anxiety Disorders 24, 353-359.

Furuta M, Sandall J, Cooper D, Bick D (2014). The relationship between severe maternal morbidity and psychological health symptoms at 6-8 weeks postpartum: a prospective cohort study in one English maternity unit. BMC Pregnancy and Childbirth 14, 133.

Garthus-Niegel S, Knoph C, Von Soest T, Nielsen CS, Eberhard-Gran M (2014a). The role of labor pain and overall birth experience in the development of posttraumatic stress symptoms: a longitudinal cohort study. Birth: Issues in Perinatal Care 41, 108-115.

Garthus-Niegel S, von Soest T, Knoph C, Simonsen TB, Torgersen L, Eberhard-Gran M (2014b). The influence of women's preferences and actual mode of delivery on posttraumatic stress symptoms following childbirth: a population-based, longitudinal study. BMC Pregnancy and Childbirth 14, 191.

Garthus-Niegel S, von Soest T, Vollrath ME, Eberhard-Gran M (2013). The impact of subjective birth experiences on post-traumatic stress symptoms: a longitudinal study. Archives of Women's Mental Health 16, 1-10.

Gavin NI, Gaynes BN, Lohr KN, Meltzer-Brody S, Gartlehner G, Swinson T (2005). Perinatal depression: a systematic review of prevalence and incidence. Obstetrics and Gynecology 106, 1071-1083.

Ghorbani M, Dolatian M, Shams J, Alavi-Majd H (2014a). Anxiety, post-traumatic stress disorder and social supports among parents of premature and full-term infants. Iranian Red Crescent Medical Journal 16, e13461.

Ghorbani M, Dolatian M, Shams J, Alavi-Majd H, Tavakolian S (2014b). Factors associated with posttraumatic stress disorder and its coping styles in parents of preterm and full-term infants. Global Journal of Health Science 6, 65-73.

Goutaudier N, Séjourné N, Rousset C, Lami C, Chabrol H (2012). Negative emotions, childbirth pain, perinatal dissociation and self-efficacy as predictors of postpartum posttraumatic stress symptoms. Journal of Reproductive and Infant Psychology 30, 352-362.

Grekin R, O'Hara MW (2014). Prevalence and risk factors of postpartum posttraumatic stress disorder: a meta-analysis. Clinical Psychology Review 34, 389-401.

Hafdahl AR (2009). Improved Fisher $z$ estimators for univariate random-effects meta-analysis of correlations. British Journal of Mathematical and Statistical Psychology 62, 233-261.

Harris R, Ayers S (2012). What makes labour and birth traumatic? A survey of intrapartum 'hotspots'. Psychology and Health 27, 1166-1177.

Hauer BJA, Wessel I, Engelhard IM, Peeters LL, Dalgleish T (2009). Prepartum autobiographical memory specificity predicts post-traumatic stress symptoms following complicated pregnancy. Memory 17, 544-556.

Hedges LV, Vevea JL (1998). Fixed- and random-effects models in meta-analysis. Psychological Methods 3, 486-504.

Hoedjes M, Berks D, Vogel I, Franx A, Visser W, Duvekot JJ, Raat H (2011). Symptoms of post-traumatic stress after preeclampsia. Journal of Psychosomatic Obstetrics and Gynaecology 32, 126-134.

Hunter JE, Schmidt FL (2004). Methods of Meta-Analysis: Correcting Error and Bias in Research Findings, 2nd edn. Sage: Newbury Park, CA.

Iles J, Slade P, Spiby H (2011). Posttraumatic stress symptoms and postpartum depression in couples after childbirth: the role of partner support and attachment. Journal of Anxiety Disorders 25, 520-530.

Keogh E, Ayers S, Francis H (2002). Does anxiety sensitivity predict post-traumatic stress symptoms following childbirth? A preliminary report. Cognitive Behaviour Therapy 31, 145-155.

Leeds L, Hargreaves I (2008). The psychological consequences of childbirth. Journal of Reproductive and Infant Psychology 26, 108-122.

Lemola S, Stadlmayr W, Grob A (2007). Maternal adjustment 5 months after birth: the impact of the subjective experience of childbirth and emotional support from the partner. Journal of Reproductive and Infant Psychology 25, 190-202.

Lev-Wiesel R, Chen R, Daphna-Tekoah S, Hod M (2009a). Past traumatic events: are they a risk factor for high-risk pregnancy, delivery complications, and postpartum posttraumatic symptoms? Journal of Women's Health 18, 119-125.

Lev-Wiesel R, Daphna-Tekoah S (2010). The role of peripartum dissociation as a predictor of posttraumatic stress symptoms following childbirth in Israeli Jewish women. Journal of Trauma and Dissociation 11, 266-283.

Lev-Wiesel R, Daphna-Tekoah S, Hallak M (2009b). Childhood sexual abuse as a predictor of birth-related posttraumatic stress and postpartum posttraumatic stress. Child Abuse and Neglect 33, 877-887.

Lipsey MW, Wilson DB (2001). Practical Meta-Analysis. Sage: Thousand Oaks, CA.

Lyons S (1998). A prospective study of post-traumatic stress symptoms 1 month following childbirth in a group of 42 first-time mothers. Journal of Reproductive and Infant Psychology 16, 91-105.

Maclean LI, McDermott MR, May CP (2000). Method of delivery and subjective distress: women's emotional 
responses to childbirth practices. Journal of Reproductive and Infant Psychology 18, 153-162.

Maggioni C, Margola D, Filippi F (2006). PTSD, risk factors, and expectations among women having a baby: a two-wave longitudinal study. Journal of Psychosomatic Obstetrics and Gynaecology 27, 81-90.

Mautner E, Stern C, Deutsch M, Nagele E, Greimel E, Lang U, Cervar-Zivkovic M (2013). The impact of resilience on psychological outcomes in women after preeclampsia: an observational cohort study. Health and Quality of Life Outcomes 11, 194.

Modarres M, Afrasiabi S, Rahnama P, Montazeri A (2012). Prevalence and risk factors of childbirth-related posttraumatic stress symptoms. BMC Pregnancy and Childbirth $12,88$.

Noyman-Veksler G, Herishanu-Gilutz S, Kofman O, Holchberg G, Shahar G (2015). Post-natal psychopathology and bonding with the infant among first-time mothers undergoing a caesarian section and vaginal delivery: sense of coherence and social support as moderators. Psychology and Health 30, 441-455.

O'Donovan A, Alcorn KL, Patrick JC, Creedy DK, Dawe S, Devilly GJ (2014). Predicting posttraumatic stress disorder after childbirth. Midwifery 30, 935-941.

Olde E, van Der Hart O, Kleber R, van Son M (2006). Posttraumatic stress following childbirth: a review. Clinical Psychology Review 26, 1-16.

Olde E, van der Hart O, Kleber RJ, van Son MJM, Wijnen HAA, Pop VJM (2005). Peritraumatic dissociation and emotions as predictors of PTSD symptoms following childbirth. Journal of Trauma and Dissociation 6, 125-142.

Onoye JM, Goebert D, Morland L, Matsu C, Wright T (2009). PTSD and postpartum mental health in a sample of Caucasian, Asian, and Pacific Islander women. Archives of Women's Mental Health 12, 393-400.

Ozer EJ, Best SR, Lipsey TL, Weiss DS (2003). Predictors of posttraumatic stress disorder and symptoms in adults: a meta-analysis. Psychological Bulletin 129, 52-73.

Polachek IS, Harari LH, Baum M, Strous RD (2012). Postpartum post-traumatic stress disorder symptoms: the uninvited birth companion. Israel Medical Association Journal 14, 347-353.

Ryding EL, Wijma K, Wijma B (1998). Psychological impact of emergency cesarean section in comparison with elective cesarean section, instrumental and normal vaginal delivery. Journal of Psychosomatic Obstetrics and Gynaecology 19, 135-144.

Sawyer A, Ayers S (2009). Post-traumatic growth in women after childbirth. Psychology and Health 24, 457-471.

Sawyer A, Ayers S, Field AP (2010). Posttraumatic growth and adjustment among individuals with cancer or HIV/ AIDS: a meta-analysis. Clinical Psychology Review 30, 436-447.

Sawyer A, Ayers S, Young D, Bradley R, Smith H (2012). Posttraumatic growth after childbirth: a prospective study. Psychology and Health 27, 362-377.

Slade P (2006). Towards a conceptual framework for understanding post-traumatic stress symptoms following childbirth and implications for further research.
Journal of Psychosomatic Obstetrics and Gynaecology 27, 99-105.

Söderquist J, Wijma B, Thorbert G, Wijma K (2009). Risk factors in pregnancy for post-traumatic stress and depression after childbirth. BJOG: An International Journal of Obstetrics and Gynaecology 116, 672-680.

Söderquist J, Wijma B, Wijma K (2006). The longitudinal course of posttraumatic stress after childbirth. Journal of Psychosomatic Obstetrics and Gynaecology 27, 113-119.

Söderquist J, Wijma K, Wijma B (2002). Traumatic stress after childbirth: the role of obstetric variables. Journal of Psychosomatic Obstetrics and Gynaecology 23, 31-39.

Sorenson DS, Tschetter L (2010). Prevalence of negative birth perception, disaffirmation, perinatal trauma symptoms, and depression among postpartum women. Perspectives in Psychiatric Care 46, 14-25.

Stramrood CA, Paarlberg KM, Huis In 't Veld EM, Berger LW, Vingerhoets AJ, Schultz WC, van Pampus MG (2011) Posttraumatic stress following childbirth in homelike- and hospital settings. Journal of Psychosomatic Obstetrics and Gynaecology 32, 88-97.

Stramrood CA, Wessel I, Doornbos B, Aarnoudse JG, van den Berg PP, Weijmar Schultz WC, van Pampus MG (2011). Posttraumatic stress disorder following preeclampsia and PROM: a prospective study with 15 months follow-up. Reproductive Sciences 18, 645-653.

Sumner L, Wong CD, Schetter HF, Myers M, Rodriguez M (2012). Predictors of posttraumatic stress disorder symptoms among low-income Latinas during pregnancy and postpartum. Psychological Trauma: Theory, Research, Practice and Policy 4, 196-203.

Suttora C, Spinelli M, Monzani D (2014). From prematurity to parenting stress: the mediating role of perinatal posttraumatic stress disorder. European Journal of Developmental Psychology 11, 478-493.

Tham V, Christensson K, Ryding EL (2007). Sense of coherence and symptoms of post-traumatic stress after emergency caesarean section. Acta Obstetricia et Gynecologica Scandinavica 86, 1090-1096.

UNdata (2011). Annual number of births (http://data.un.org/ Data.aspx?d=SOWC\&f=inID\%3A75). Accessed October 2013. van Son MJM, Verkerk G, van der Hart O, Komproe I, Pop V (2005). Prenatal depression, mode of delivery and perinatal dissociation as predictors of postpartum posttraumatic stress: an empirical study. Clinical Psychology and Psychotherapy 12, 297-312.

Verreault N, Da Costa D, Marchand A, Ireland K, Banack H, Dritsa M, Khalifé S (2012). PTSD following childbirth: a prospective study of incidence and risk factors in Canadian women. Journal of Psychosomatic Research 73, 257-263.

Viechtbauer W (2010). Conducting meta-analyses in R with the Metafor package. Journal of Statistical Software 36, 1-48.

Vossbeck-Elsebusch AN, Freisfeld C, Ehring T (2014). Predictors of posttraumatic stress symptoms following childbirth. BMC Psychiatry 14, 200.

Warmelink JC, Stramrood CAI, Paarlberg KM, Haisma HH, Vingerhoets AJJM, Weijmar Schultz WCM, van Pampus MG (2012). Posttraumatic stress disorder, anxiety and depression following pregnancies conceived through 
fertility treatments: the effects of medically assisted conception on postpartum well-being. Journal of Reproductive Medicine 57, 115-122.

Wenzel A, Haugen E, Jackson L, Brendle J (2005). Anxiety symptoms and disorders at eight weeks postpartum. Anxiety Disorders 19, 295-311.

Wijma K, Ryding EL, Wijma B (2002). Predicting psychological well-being after emergency caesarean section: a preliminary study. Journal of Reproductive and Infant Psychology 20, 25-36.
Wijma K, Söderquist J, Wijma B (1997). Posttraumatic stress disorder after childbirth: a cross sectional study. Journal of Anxiety Disorders 11, 587-597.

World Health Organization (2005). Facts and Figures from the World Health Report 2005. World Health Organization: Geneva.

Zaers S, Waschke M, Ehlert U (2008). Depressive symptoms and symptoms of PTSD in women after childbirth. Journal of Psychosomatic Obstetrics and Gynaecology 29, 61-71. 